\title{
SHAKE TABLE SEISMIC PERFORMANCE OF BAMBOO FRAME AND STEEL FRAME
}

\author{
Kavitha Raj \\ Department of Civil Engineering \\ PES College of Engineering, Mandya, Karnataka, \\ India
}

\begin{abstract}
Seismic performance is an evaluation of building structures ability to sustain its due functions such as safety and serviceability at and after a particular earthquake. The study of the generation, propagation and recording of elastic waves in the earth is termed as seismology. Earthquakes are part of this environment. Apart from these, destruction of life and property, they can have serious indirect consequences. The exact simulation of earthquake motion has been a serious challenge to researchers and engineers. To overcome these problems caused by earthquakes various test have conducted on models before the construction of the full structure. We are making an attempt to evaluate the best frame system for resisting earthquakes. The models are analysed in ETABS software and experimentally analysed using shake table. Shake table are used in many research work as it produces the same effects that earthquake produces. Shake table are used to study the dynamic effects like frequency, drift and displacement of different frames. Based on this studies the performance of the bamboo frame over steel frame is evaluated and optimized the best frame effectively to withstand seismic activity.
\end{abstract}

Keywords: seismic performance, Etabs, bamboo frame, dynamic effects, shake table.

\section{INTRODUCTION}

Seismic performance is an evaluation of building structures ability to sustain its due functions such as safety and serviceability at and after a particular earthquake. The subset of seismic analysis is the structural analysis and is the calculation of the response of a building structure to earthquakes.

The infrastructure is developing at a rapid pace with the growing needs of the community and the losses experienced by the earthquake hazards are increasing tremendously with time. From the past few decades, earthquake experiences all over the world have become major concern for the researchers and engineers. Several physical (full scale and reduced scale) and numerical models are developed and are being developed to study various problems related to seismic related basic soil mechanics problems and geotechnical structures.

\author{
Sandeep Kumar D S \\ Department of Civil Engineering \\ PES College of Engineering, Mandya, Karnataka, \\ India
}

In the northeast Indian hill region, the recent 2004 Sikkim earthquake demonstrated the vulnerability of existing and newly constructed masonry and concrete structures. India has Witnessed significant and damaging impacts of several medium and high intensity earthquakes in the past years.

Out of these, the Bhuj earthquake (2001), which has severely affected Ahmedabad city and surroundings, is the very recent one which attracted the attention of the most of the engineers, scientists and also professional practitioners working in the area of earthquake engineering. To minimize the damage caused due to earthquake on various structures, performance assessment of these structures under seismic loading is required, which can be acquired through physical model tests. One of the purposes of the physical modelling is to generate data which can be used to validate numerical and analytical procedures which can be used for simulation and then extrapolating from model to the prototype scale. There are several experimental techniques that can be used to test the response of structures and soil or rock slopes to verify their seismic performance, one of which is the use of an earthquake shaking table. Shake table are an essential tool for assessing the behaviour of structural components, the whole system works similar to those induced in real earthquake.

\section{OBJECTIVE}

The objective of this study:

1. To determine the various seismic parameters like drift, frequency and displacement for the two frame systems (bamboo frame and steel frames)

2. To evaluate the performance of the bamboo frame over steel frame.

3. To optimize the best frame system effectively to withstand seismic activity.

\section{METHODOLOGY}

Methodology steps follows:

1. Literature Review

2. Similitude Study

3. Seismic analysis of models using Etabs software

4. Preparation of model using Bamboo and MS steel

5. Testing models in shake table

6. Studying parameters like frequency, displacement...etc. 


\section{International Journal of Engineering Applied Sciences and Technology, 2019 \\ Vol. 4, Issue 2, ISSN No. 2455-2143, Pages 59-66 \\ Published Online June 2019 in IJEAST (http://www.ijeast.com)}

7. Comparison of results obtained from bamboo frame steel frame.

8. Conclusion

\section{MODEL PREPARATION}

\section{MODELLING IN ETABS}

A simple steel frame of size $300 \mathrm{~mm} * 150 \mathrm{~mm}$ single bay was modelled in Etabs, the details of the models are described below

Table I

\begin{tabular}{|l|l|}
\hline Number of storey & $\mathrm{G}+2$ \\
\hline Column size & $25 \mathrm{~mm}^{*} 5 \mathrm{~mm}$ \\
\hline Plate size & $150 \mathrm{~mm}^{*} 10 \mathrm{~mm}$ \\
\hline Plate dimensions & $300 \mathrm{~mm}^{*} 150 \mathrm{~mm}$ \\
\hline Storey height & $500 \mathrm{~mm}$ \\
\hline Material & MS Steel \\
\hline
\end{tabular}

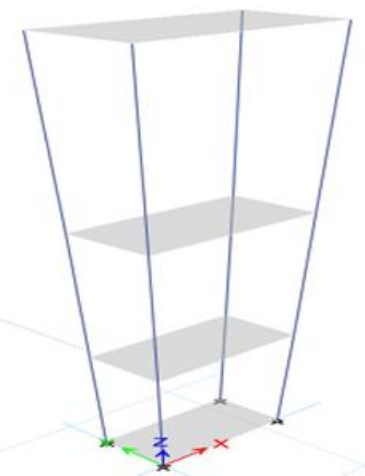

Fig 1. Steel frame

The seismic details of the steel frame

Seismic details:

Referring to IS code - 1893 (part 1):2002

Seismic zone factor, $\mathrm{Z}-0.36$

Seismic zone - V

Importance factor - I - 1

Reduction factor - $\mathrm{R}-5$

\section{BAMBOO MODEL PREPARATION}

After deciding the scaling factor the preparation of the scaled model is done. The model is prepared as follows,

1. At first the prototype building is considered.

2. The scaling of prototype building is done then the model with precise and required sizes is obtained.

3. Once the model size is been decided we moved to the preparation of model using bamboo.

The following fig shows the dimensions of prototype and model.

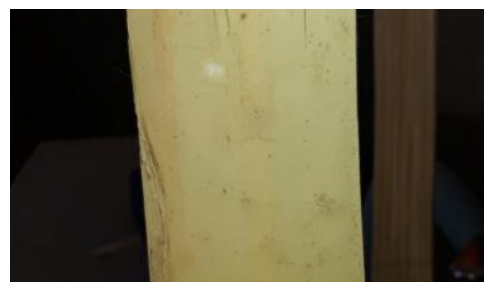

Fig 2: Cross section of bamboo column

4. The main components of model are columns, base and storey plates, steel nails, bamboo (in case of bamboo model) and steel (in case of steel model)

5. We searched for the bamboo's and collected required amount of bamboo and cleaned it.

6. Then the bamboo is cut into desired shape and size.

7. The columns prepared using bamboo is of height-500 $\mathrm{mm}$ (each storey height), thickness-5mm, and width-25mm, are formed using bamboo.

8. The plates of length-300 mm, width- $150 \mathrm{~mm}$, and thickness-10 mm, are made. Here as the thickness and width of plate is more we attached two bamboo strips to achieve the thickness and 5 bamboo strips of $30 \mathrm{~mm}$ width to achieve width of $150 \mathrm{~mm}$. To attach the bamboo strips we used glue and steel wires.

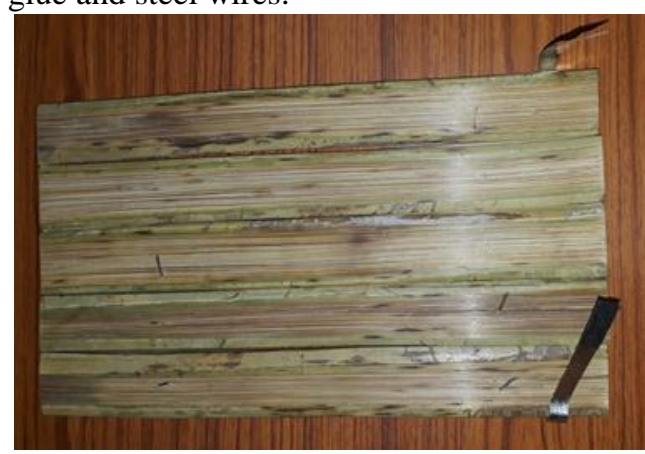

Fig 3: Elements of plate

9. In the base plate the holes of $12 \mathrm{~mm}$ diameter are made to fit the model safely on to the shake table (here $12 \mathrm{~mm}$ diameter bolts are used)

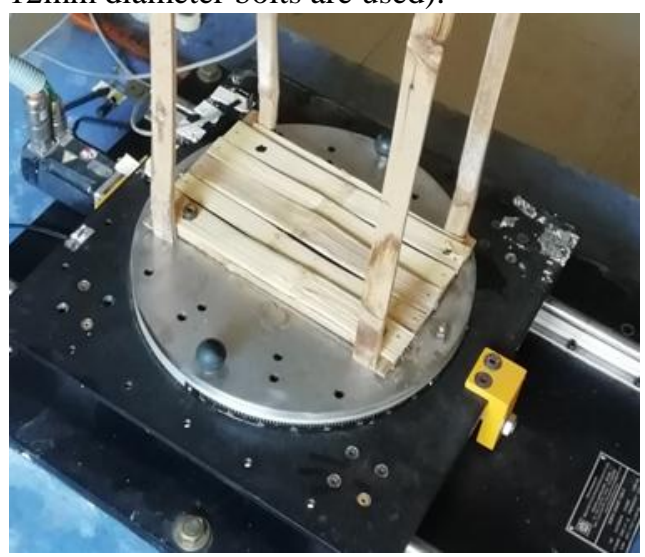

Fig 4: Connection of model with shake table 


\section{International Journal of Engineering Applied Sciences and Technology, 2019 \\ Vol. 4, Issue 2, ISSN No. 2455-2143, Pages 122-129 \\ Published Online June 2019 in IJEAST (http://www.ijeast.com)}

10. Once the individual elements of model are prepared they are joined and made into a 3 storey single bay replica of a building. Here the steel nails are used to join the individual elements.

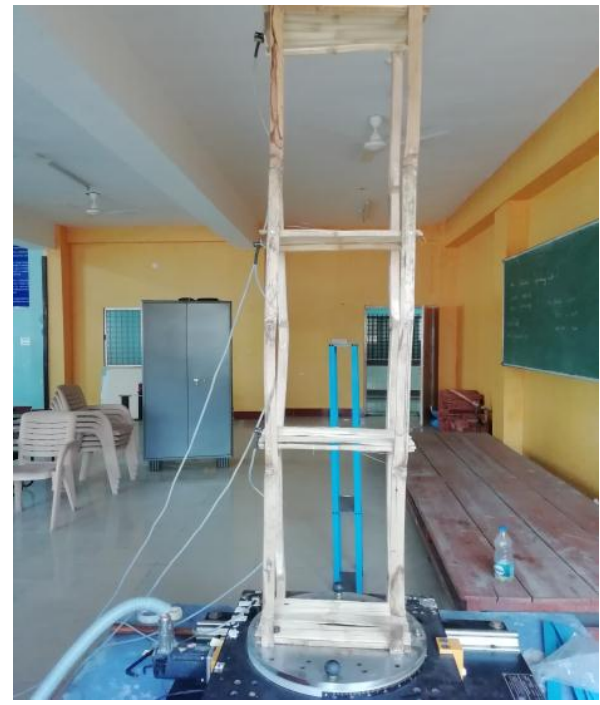

Fig 5: Final Bamboo model

\section{STEEL MODEL PREPARATION}

After deciding the scaling factor the preparation of the scaled model is done. The model is prepared as follows,

1. At first the prototype frame is considered.

2. The scaling of prototype frame is done then the model with precise and required sizes is obtained.

3. Once the model size is been decided we moved to the preparation of model using mild steel.

The following fig shows the dimensions of steel frame

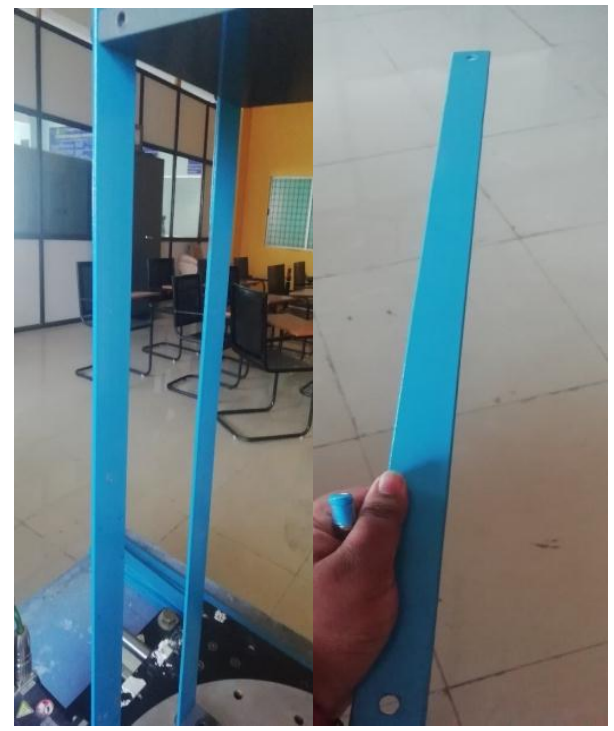

Fig 6: Cross section of Steel columns
The main components of model are steel columns, base and storey plates, nuts and screws.

The columns made from steel which are of height-500 mm (each storey height), thickness-5mm, and width-25mm, are formed.

The plates of length-300 mm, width-150 mm, and thickness-10mm, are made. To attach the steel plate we used screws and nuts.

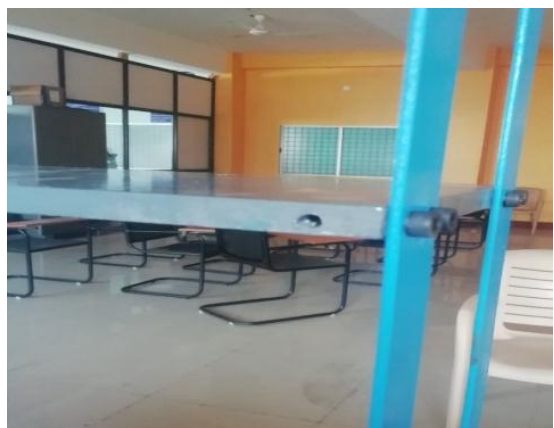

Fig 7: plate connected to column using bolts ( $6 \mathrm{~mm} \mathrm{dia)}$

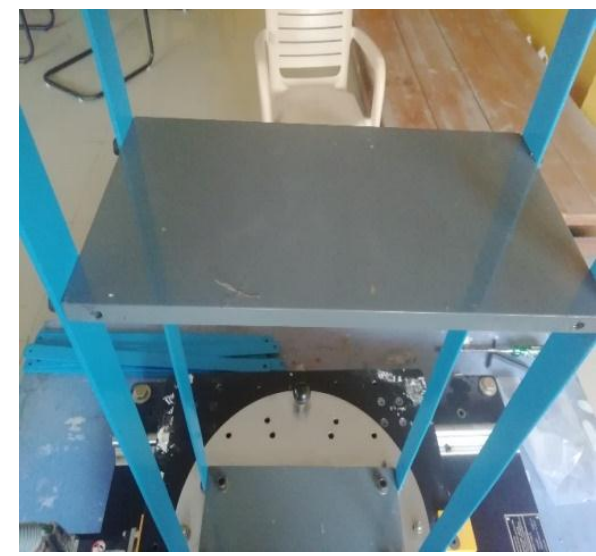

Fig 8: steel plate of thickness $10 \mathrm{~mm}$

In the base plate the holes of $12 \mathrm{~mm}$ diameter are made to fit the model safely on to the shake table (here $12 \mathrm{~mm}$ diameter bolts are used).

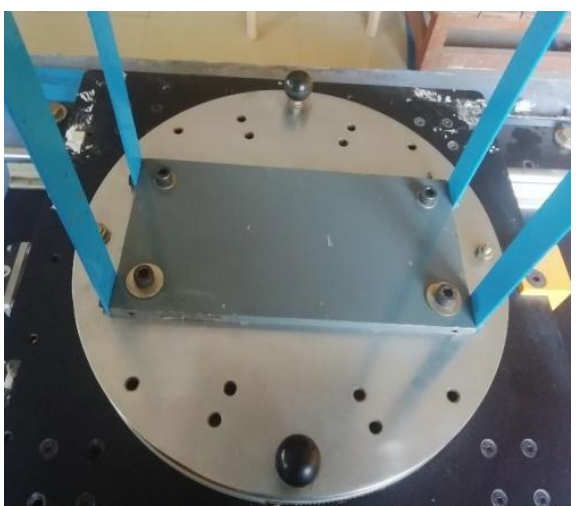

Fig 9: Bottom plate connected to shake table 
Once the individual elements of model are prepared they are joined and made into a 3 storey single bay

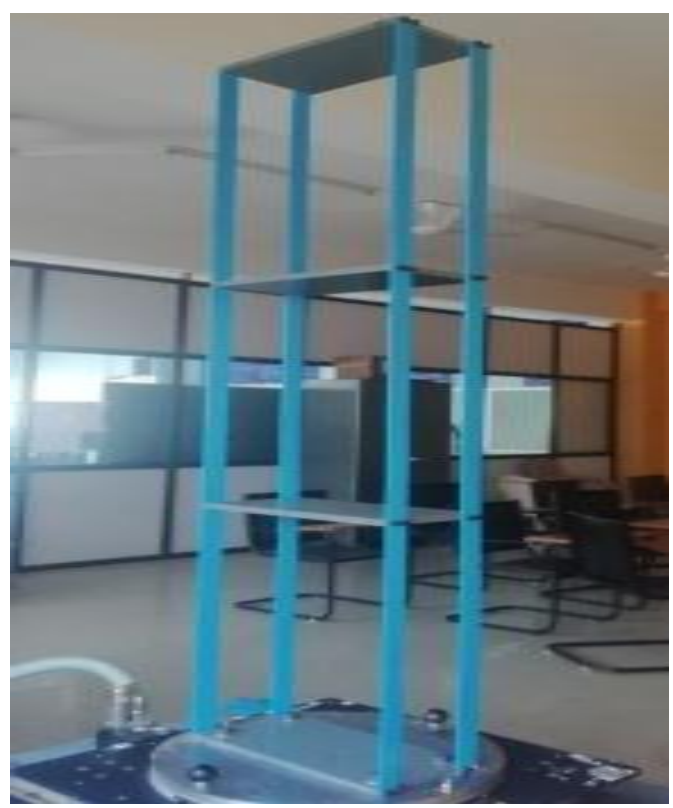

Fig 10 : Steel frames

\section{TESTING USING SHAKE TABLE}

The testing procedure using shake table is as follows. It works on two soft-wares.

1. Launch the Kampana Vibration Analyser Software by clicking the Icon on the on the Desktop.

2. After the application launches, click on setting and select the appropriate port in the com port tab, also select the channels and grid settings.

3. Press the start button and let the time domain data get plotted.

4. Verify the frequency value. (Any change in frequency should have a minimum of 20 second off-time margin, half a minute could be taken as reference).

5. Use the keys to scale the time and voltage scale for the display windows.

6. Click Filter ON, then filter settings to select the filter parameters, edit the values as required and click apply.

7. You can see the change in the time domain waveform.

8. Similarly corresponding change will be visible in frequency domain.

9. Check the vibration parameters displayed on the control window.

10. Change the frequency to a different value and follow the steps from step 4 to step 10.

11. Repeat the procedure from step 4 to step 10 for further experiment.

12. Stop the experiment by clicking on the stop button.

13. Browse the files that are saved by default, verify the date and time of file creation.

14. Read the data and plot the data in offline mode for verification.
15. Export the acceleration data and verify the generated file by checking the time histories of acceleration, velocity and displacement.

\section{RESULTS AND DISCUSSIONS}

An experiment was carried on shake table for bamboo frame and Steel frame where the frequency ranges from 1 to 8 $\mathrm{Hz}$ of 50 cycles. The results are obtained in excel sheets. Graphs are plotted for respective values.

\section{A.BAMBOO FRAME}

Table 1- Displacement in ' $\mathrm{mm}$ ' for $\mathrm{X}$ direction

\begin{tabular}{|c|c|c|c|c|}
\hline & \multicolumn{4}{|c|}{ X Direction } \\
\hline Frequency & CH 1 & CH 2 & CH 3 & CH 4 \\
\hline 1 & 19.974 & 33.952 & 56.256 & 52.489 \\
\hline 2 & 43.403 & 33.952 & 56.256 & 54.251 \\
\hline 3 & 7.087 & 23.019 & 11.235 & 23.039 \\
\hline 4 & 32.564 & 50.79 & 11.239 & 74.226 \\
\hline 5 & 26.984 & 31.339 & 43.273 & 46.554 \\
\hline 6 & 86.136 & 93.178 & 144.621 & 84.254 \\
\hline 7 & 86.136 & 93.178 & 144.621 & 161.083 \\
\hline 8 & 86.136 & 93.178 & 144.621 & 161.083 \\
\hline
\end{tabular}

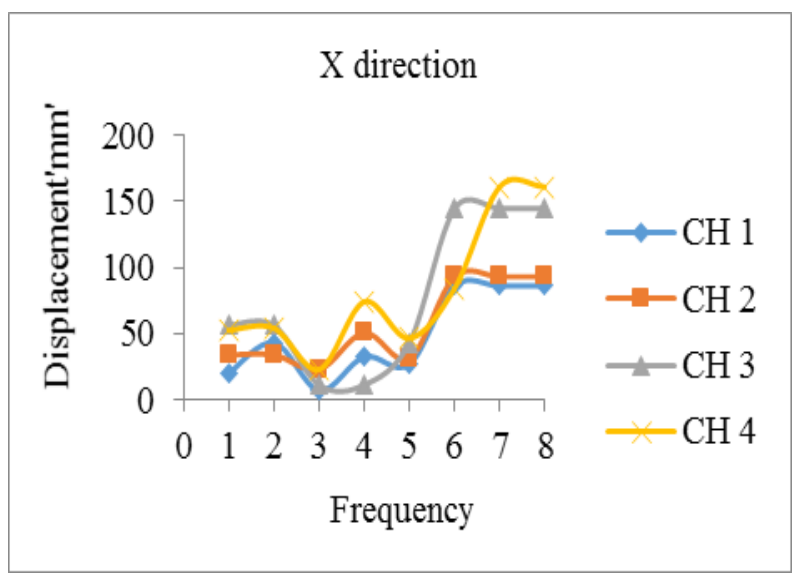

Fig 11: Displacement vs. frequency graph

Table 2 - Displacement in 'mm' for Y direction

\begin{tabular}{|c|c|c|c|c|}
\hline & \multicolumn{4}{|c|}{ Y Direction } \\
\hline Frequency & CH 1 & CH 2 & CH 3 & CH 4 \\
\hline 1 & 38.551 & 43.163 & 33.952 & 20.859 \\
\hline 2 & 41.038 & 43.163 & 33.952 & 43.339 \\
\hline 3 & 3.456 & 2.681 & 23.019 & 27.31 \\
\hline 4 & 7.028 & 15.06 & 50.79 & 6.16 \\
\hline 5 & 16.484 & 29.899 & 31.399 & 41.535 \\
\hline 6 & 41.536 & 99.372 & 93.178 & 82.146 \\
\hline 7 & 41.536 & 99.372 & 93.178 & 241.384 \\
\hline 8 & 41.536 & 99.372 & 93.178 & 241.384 \\
\hline
\end{tabular}




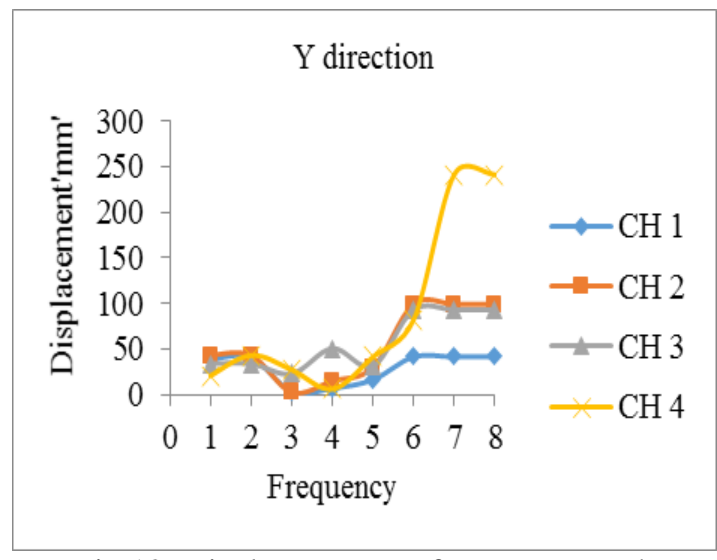

Fig 12: Displacement vs. frequency graph

Table 3- Displacement in ' $\mathrm{mm}$ ' for $\mathrm{Z}$ direction

\begin{tabular}{|c|c|c|c|c|}
\hline & \multicolumn{4}{|c|}{ Z Direction } \\
\hline Frequency & CH 1 & CH 2 & CH 3 & CH 4 \\
\hline 1 & 2.837 & 16.158 & 0.587 & 40.222 \\
\hline 2 & 3.591 & 42.955 & 39.226 & 40.222 \\
\hline 3 & 5.34 & 2.439 & 1.813 & 6.558 \\
\hline 4 & 6.036 & 7.724 & 7.724 & 6.726 \\
\hline 5 & 7.785 & 10.796 & 39.178 & 36.997 \\
\hline 6 & 8.158 & 10.796 & 133.756 & 54.498 \\
\hline 7 & 8.158 & 15.026 & 133.756 & 321.347 \\
\hline 8 & 8.158 & 15.026 & 133.756 & 321.347 \\
\hline
\end{tabular}

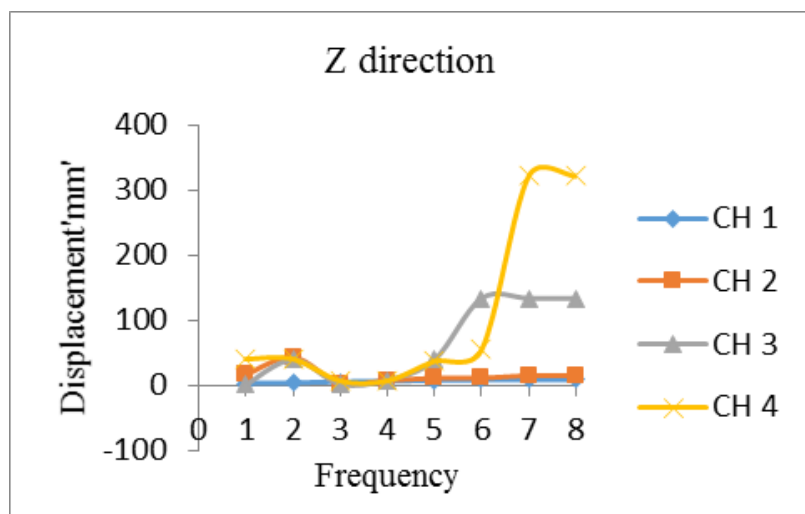

Fig 13: Displacement vs. frequency graph

The figure shows the Displacement vs Frequency variation graph. The above graph is drawn using the values of displacement obtained for varying frequencies for $\mathrm{X}, \mathrm{Y}$ and $\mathrm{Z}$ direction of $\mathrm{CH} 1,2,3$ and 4 . Here the variation of frequency is between $1-6 \mathrm{~Hz}$. While doing the test using shake table for

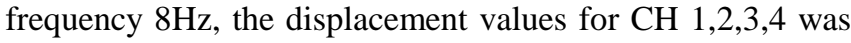
maximum.

\section{B.STEEL FRAME}

Table 4- Displacement in ' $\mathrm{mm}$ ' for $\mathrm{X}$ direction

\begin{tabular}{|l|c|c|c|c|}
\hline \multicolumn{5}{|c|}{ X Direction } \\
\hline Frequency & CH 1 & CH 2 & CH 3 & CH 4 \\
\hline
\end{tabular}

\begin{tabular}{|c|c|c|c|c|}
\hline 1 & 12.059 & 20.752 & 10.566 & 41.274 \\
\hline 2 & 40.469 & 80.792 & 49.047 & 36.486 \\
\hline 3 & 40.469 & 80.792 & 49.047 & 36.486 \\
\hline 4 & 50.583 & 42.96 & 45.464 & 274.607 \\
\hline 5 & 51.45 & 40.551 & 50.324 & 274.604 \\
\hline 6 & 51.45 & 40.551 & 50.324 & 274.607 \\
\hline
\end{tabular}

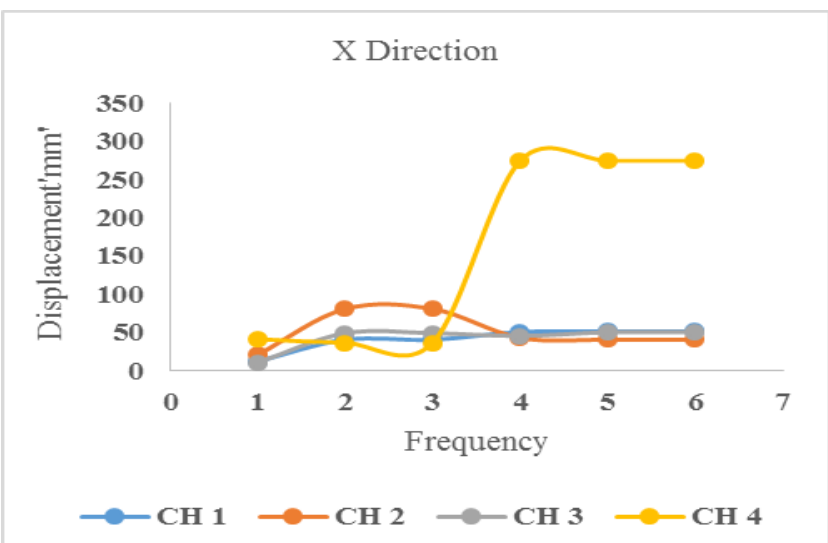

Fig 14: Displacement vs. frequency graph

Table 5- Displacement in 'mm' for Y direction

\begin{tabular}{|c|c|c|c|c|}
\hline \multicolumn{5}{|c|}{ Y Direction } \\
\hline Frequency & CH 1 & CH 2 & CH 3 & CH 4 \\
\hline 1 & 24.277 & 22.663 & 39.475 & 3.074 \\
\hline 2 & 65.774 & 26.207 & 106.901 & 42.864 \\
\hline 3 & 65.774 & 26.207 & 106.901 & 43.99 \\
\hline 4 & 41.003 & 7.753 & 40.952 & 338.869 \\
\hline 5 & 9.599 & 9.753 & 38.112 & 338.869 \\
\hline 6 & 27.017 & 9.753 & 38.112 & 338.869 \\
\hline
\end{tabular}

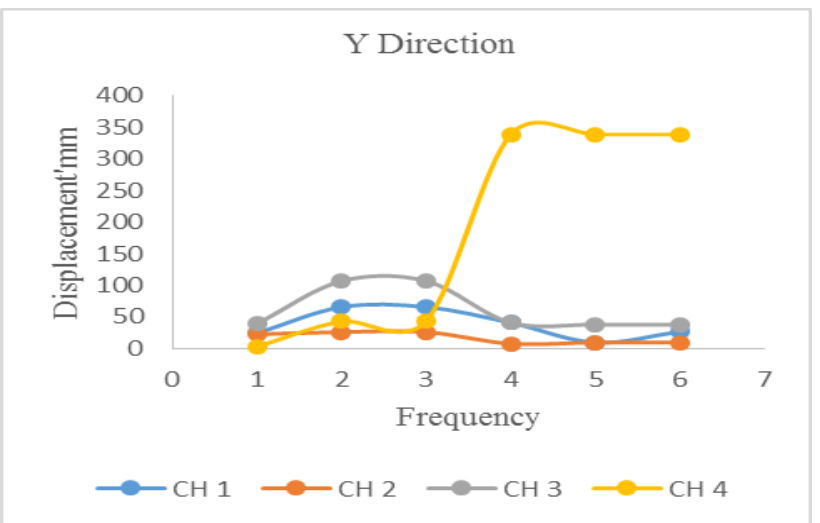

Fig 15: Displacement vs. frequency graph

Table 6- Displacement in ' $\mathrm{mm}$ ' for $\mathrm{Z}$ direction

\begin{tabular}{|c|c|c|c|c|}
\hline \multicolumn{5}{|c|}{ Z Direction } \\
\hline Frequency & CH 1 & CH 2 & CH 3 & CH 4 \\
\hline 1 & 2.808 & 11.979 & 30.516 & 37.331 \\
\hline 2 & 2.808 & 57.599 & 63.179 & 40.116 \\
\hline 3 & 2.808 & 57.599 & 63.179 & 40.116 \\
\hline 4 & 2.678 & 5.699 & 18.723 & 158.056 \\
\hline 5 & 8.678 & 6.147 & 19.843 & 158.056 \\
\hline 6 & 10.849 & 6.678 & 20.033 & 158.056 \\
\hline
\end{tabular}




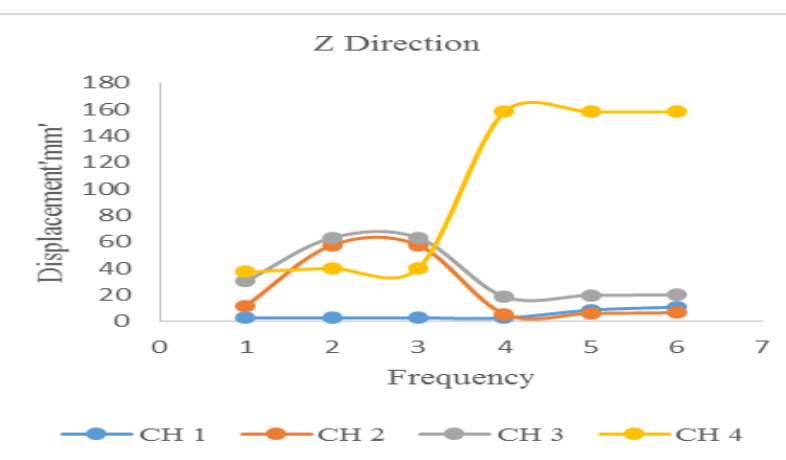

Fig 16: Displacement vs. frequency graph

.The figure shows the Displacement vs Frequency variation graph. The above graph is drawn using the values of displacement obtained for varying frequencies for $\mathrm{X}, \mathrm{Y}$ and $\mathrm{Z}$ direction of $\mathrm{CH} 1,2,3$ and 4 . Here the variation of frequency is between $1-6 \mathrm{~Hz}$. While doing the test using shake table for frequency $4 \mathrm{~Hz}$, the displacement values for $\mathrm{CH} 1,2,3,4$ was maximum.

Based on the results, it is observed that the bamboo framed structure was resisted the seismic loads safely till the frequency $8 \mathrm{~Hz}$ whereas the steel framed structure was till the frequency $4 \mathrm{~Hz}$

\section{C.BAMBOO FRAMED STRUCTURE (FREQUENCY 8HZ)}

An experiment was carried on shake table for bamboo frame, where the frequency ranges from 1 to $8 \mathrm{~Hz}$ of 50 cycles. For time interval of 10 seconds and 30 seconds the displacement values were obtained. The results are obtained in excel sheets. Graphs are plotted for respective values.

Table 7- Displacement in 'mm' X Direction

\begin{tabular}{|c|c|c|c|c|}
\hline & \multicolumn{4}{|c|}{ X Direction } \\
\hline Time(S) & CH1 & CH2 & CH3 & CH4 \\
\hline 0 & 0 & 0 & 0 & 0 \\
\hline 30 & 0.032 & 0.034 & -0.047 & -0.095 \\
\hline 60 & 1.143 & 1.045 & 1.633 & 1.232 \\
\hline 90 & 3.261 & 3.05 & 5.147 & 3.291 \\
\hline 120 & 0.089 & 0.026 & 0.051 & 0.041 \\
\hline 150 & -9.817 & -0.063 & 6.242 & -0.404 \\
\hline 180 & 1.4 & -0.052 & -0.018 & 0.004 \\
\hline
\end{tabular}

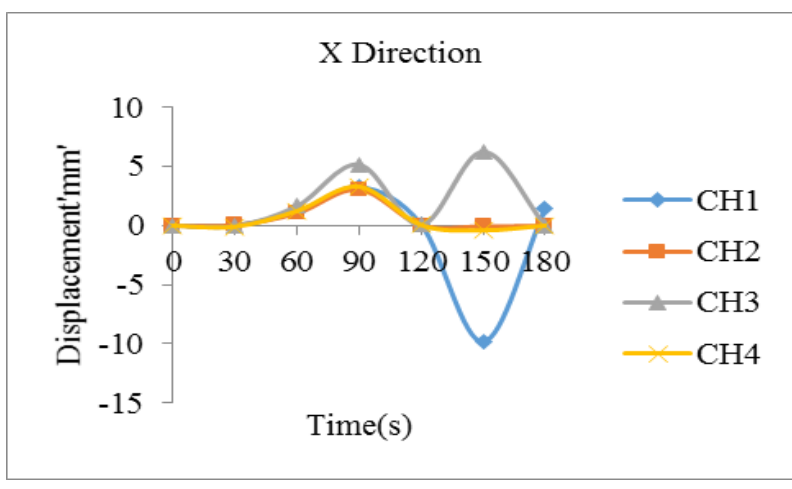

Fig 17: Displacement vs. Time graph

Table 8- Displacement in 'mm' Y Direction

\begin{tabular}{|c|c|c|c|c|}
\hline & \multicolumn{4}{|c|}{ Y Direction } \\
\hline Time(s) & CH1 & CH2 & CH3 & CH4 \\
\hline 0 & 0 & 0 & 0 & 0 \\
\hline 30 & 0.373 & -0.017 & -0.015 & 0.121 \\
\hline 60 & 1.1 & 1.25 & 0.711 & 0.657 \\
\hline 90 & 3.084 & 3.63 & 1.563 & 1.861 \\
\hline 120 & 0.041 & 0.028 & 0.049 & 0.196 \\
\hline 150 & -1.111 & -4.083 & -1.867 & 0.547 \\
\hline 180 & -4.254 & 0.025 & 0.003 & -0.054 \\
\hline
\end{tabular}

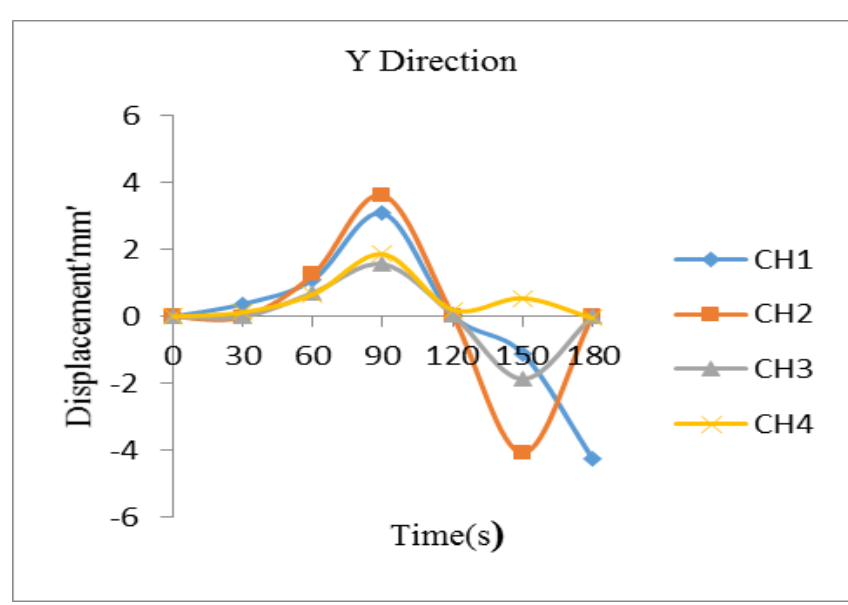

Fig 18: Displacement vs. Time graph

Table 9- Displacement in 'mm' Z Direction

\begin{tabular}{|c|c|c|c|c|}
\hline & \multicolumn{4}{|c|}{ Z Direction } \\
\hline Time(s) & CH1 & CH2 & CH3 & CH4 \\
\hline 0 & 0 & 0 & 0 & 0 \\
\hline 30 & -0.412 & -0.068 & -0.084 & -0.049 \\
\hline 60 & 0.806 & -0.403 & 1.573 & 0.25 \\
\hline 90 & 1.931 & -0.232 & 5.015 & 0.099 \\
\hline 120 & 0.15 & -0.093 & -0.236 & -0.221 \\
\hline 150 & 0.654 & -2.109 & 3.58 & -2.07 \\
\hline 180 & 1.717 & -0.067 & 0.073 & -0.329 \\
\hline
\end{tabular}




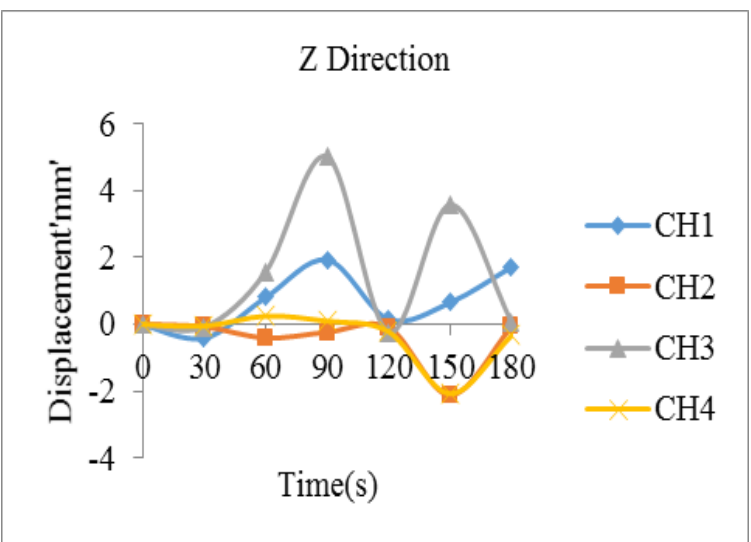

Fig 19: Displacement vs. Time graph

\section{STEEL FRAMED STRUCTURE (FREQUENCY 4HZ)}

Table 10- Displacement in 'mm' X Direction

\begin{tabular}{|c|c|c|c|c|}
\hline & \multicolumn{4}{|c|}{ X Direction } \\
\hline Time(s) & CH 1 & CH 2 & CH 3 & CH 4 \\
\hline 0 & 0 & 0 & 0 & 0 \\
\hline 30 & -1.104 & 0.475 & 0.381 & -0.443 \\
\hline 60 & -0.637 & -0.618 & 0.629 & -0.827 \\
\hline 90 & 2.549 & 1.295 & -0.015 & -0.362 \\
\hline 120 & 0.06 & -0.13 & 0.002 & -0.632 \\
\hline 150 & -2.697 & 11.238 & -20.126 & 28.63 \\
\hline 180 & -0.241 & -0.107 & 0.221 & -0.629 \\
\hline
\end{tabular}

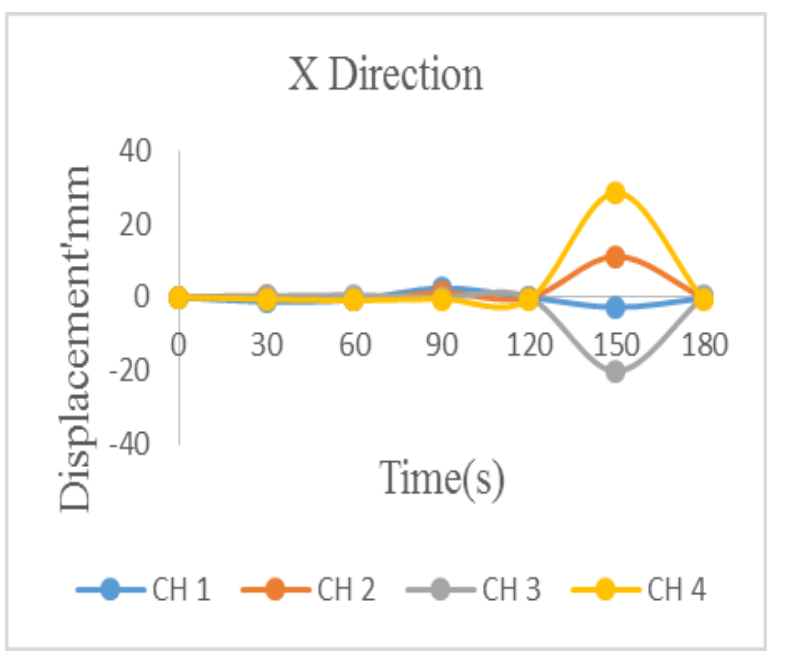

Fig 20: Displacement vs. Time graph

Table 11- Displacement in 'mm' Y Direction

\begin{tabular}{|c|c|c|c|c|}
\hline & \multicolumn{4}{|c|}{ Y Direction } \\
\hline Time(s) & CH 1 & CH 2 & CH 3 & CH 4 \\
\hline 0 & 0 & 0 & 0 & 0 \\
\hline 30 & -1.019 & 0.093 & 0.007 & 0.024 \\
\hline 60 & -1.586 & 0.086 & -0.099 & -0.166 \\
\hline
\end{tabular}

\begin{tabular}{|c|c|c|c|c|}
\hline 90 & 3.896 & -0.014 & 0.212 & -0.088 \\
\hline 120 & 0.243 & 0.017 & 0.158 & -0.061 \\
\hline 150 & -4.323 & 0.132 & -0.391 & 3.85 \\
\hline 180 & 0.03 & 0.096 & -0.097 & -0.018 \\
\hline
\end{tabular}

Y Direction

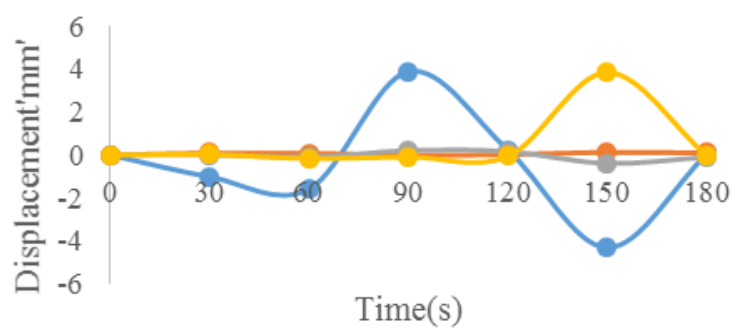

$\mathrm{CH} 1-\mathrm{CH}_{2}-\mathrm{CH}_{3}-\mathrm{CH} 4$

Fig 21: Displacement vs. Time graph

Table 12- Displacement in ' $m m$ ' Z Direction

\begin{tabular}{|c|c|c|c|c|}
\hline & \multicolumn{4}{|c|}{ Z Direction } \\
\hline Time(s) & CH 1 & CH 2 & CH 3 & CH 4 \\
\hline 0 & 0 & 0 & 0 & 0 \\
\hline 30 & 1.028 & -0.206 & -0.089 & -0.335 \\
\hline 60 & 1.448 & 0.123 & -0.231 & -0.063 \\
\hline 90 & -5.241 & 0.322 & -0.046 & -0.151 \\
\hline 120 & 0.247 & -0.09 & -0.19 & -0.053 \\
\hline 150 & 5.994 & 2.186 & 1.563 & 6.107 \\
\hline 180 & -0.068 & -0.173 & 0.036 & -0.246 \\
\hline
\end{tabular}

Z Direction

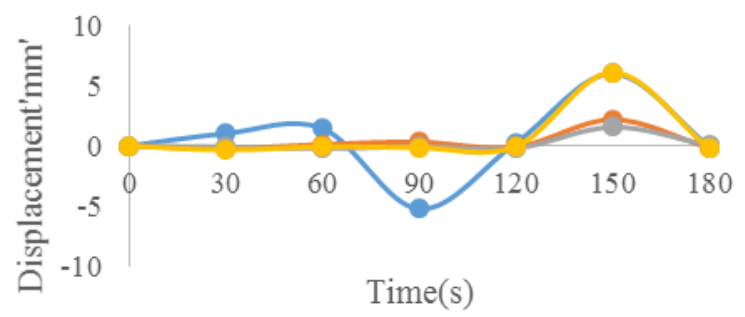

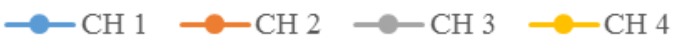

Fig 22: Displacement vs. Time graph

These figures show the Displacement vs Time variation graph. The above graph is drawn using the values of displacement obtained for frequencies $4 \mathrm{~Hz}$ of $\mathrm{X}, \mathrm{Y}$ and $\mathrm{Z}$ direction for $\mathrm{CH} 1,2,3$ and 4 . While doing the test using shake table the displacement values for $\mathrm{CH} \mathrm{1,2,3} \mathrm{and} 4$ at $60 \mathrm{sec}$ was minimum later at $150 \mathrm{sec}$ the displacement was maximum. 


\section{International Journal of Engineering Applied Sciences and Technology, 2019 \\ Vol. 4, Issue 2, ISSN No. 2455-2143, Pages 59-66 \\ Published Online June 2019 in IJEAST (http://www.ijeast.com)}

\section{CONCLUSION}

Based on the results, the bamboo framed structure was resisted the seismic loads safely till the frequency $8 \mathrm{~Hz}$ whereas the steel framed structure was till the frequency $4 \mathrm{~Hz}$. The maximum displacement was at channel 4 of $\mathrm{X}, \mathrm{Y}$ and $\mathrm{Z}$ direction (161.083mm,241.384mm and $321.347 \mathrm{~mm}$ ) at frequency $8 \mathrm{~Hz}$ for bamboo framed structure and for steel framed structure the maximum displacement was at channel 4 of $\mathrm{X}, \mathrm{Y}$ and $\mathrm{Z}$ direction $(274.607 \mathrm{~mm} 3 \quad 38.869 \mathrm{~mm}$ and 158.056) at frequency $4 \mathrm{~Hz}$.

The maximum displacement $(0.654 \mathrm{~mm},-2.109 \mathrm{~mm}, 3.58 \mathrm{~mm}$ and $-2.07 \mathrm{~mm}$ ) was at time $150 \mathrm{sec}$ for frequency $8 \mathrm{~Hz}$ for bamboo framed structure, whereas the maximum displacement $(5.994 \mathrm{~mm}, 2.186 \mathrm{~mm}, 1.563 \mathrm{~mm}, 6.107 \mathrm{~mm})$ was at time $150 \mathrm{sec}$ for frequency $4 \mathrm{~Hz}$ for steel framed structure

\section{REFERENCES}

[1] Li CS, Lam SSE, Zhang MZ and Wong YL, Shaking Table Test of a 1:20 Scale High-rise Building with a Transfer Plate System. Journal of Structural Engineering, ASCE. 132(11): 1732-1744. (2006).

[2] Buland P etal, Shaking table testing, in Recent Advances in earthquake Engineering and Structural Dynamics. Ed. V.E. Davidovici, 795-805 Quest Editions, Nantes, France. 1992

[3] Apostolou, M., Gazetas, G., and Garini, E., Seismic response of slender rigid structures with foundation uplifting. Soil Dynamics and Earthquake Engineering. (2007).

[4] Shaking table test of steel frame structures subjected to near-fault ground motions, 13th World Conference on Earthquake Engineering Vancouver, B.C., Canada August 1-6, 2004 Paper No. 3054

[5] A. P. Kulkarni, M. K. Sawant, M. S. Shindepatil and D. Y. Patil , Experimental Study using Earthquake Shake Table, Institute of Engineering, Management \& Research, Akurdi, Pune: 411044.

[6] Sachin Dhiman etal, Behaviour of Multi-storey Steel Structure with Different Types of Bracing Systems (A Software Approach) International Refereed Journal of Engineering and Science (IRJES) ISSN (Online) 2319-183X, (Print) 2319-1821 Volume 4, Issue 1 (January 2015), PP.70-82

[7] M. N. Chimeh and P. Homami Efficiency of bracing systems for seismic rehabilitation of steel structures, Kharazmi (Tarbiat Moallem) University, Tehran, Iran.

[8] Tian Chunyu etal, Shaking table model test on Shanghai Towers, International Journal of High Raise buildings, March 2013,vol 2,No.79-83

[9] Madhusudan G Seismic performance of concentric braced steel frames from pushover analysis, IOSR Journal of Mechanical and Civil Engineering (IOSR-JMCE).

[10] András Darabant, etal, Bamboo biomass yield and feedstock characteristics of energy plantations in
Thailand, European Geosciences Union General Assembly 2014, EGU 2014.

[11] Milenium technologies pvt.ltd, shake tables- loading frames.

[12] Pankaj Agrawal, Manish Shirkhande, "Earthquake Resistant Design of Structure". 